Research Article

\title{
Working Memory in Collegiate Athletes and Non-Athletes: A Comparison of Team-Sports Athletes, Solo-Sports Athletes, Frequent Exercisers and Infrequent Exercisers
}

Tara T. Lineweaver ${ }^{1}$, Suneeta Kercood ${ }^{1, *}$, Elyse B. Morgan ${ }^{2}$, Shelby L. Rampone ${ }^{1}$, Colleen C. Frank $^{3}$, Scott A. McLuckie ${ }^{4}$, Mack F. Reed ${ }^{1}$

1. Butler University, Indianapolis, IN, USA; E-Mails: tlinewea@butler.edu; skercood@butler.edu; shelbytrue@gmail.com; mack.reed93@gmail.com

2. Indiana University Medical School, Indianapolis, IN, USA; E-Mail: ebmorgan@iupui.edu

3. University of Michigan, Ann Arbor, MI, USA; E-Mail: ccfrank@umich.edu

4. McLuckie, External Consultant, USA, Country; E-Mail: scott@mcluckie.net

* Correspondence: Suneeta Kercood; E-Mail: skercood@butler.edu

Academic Editor: Paul D. Loprinzi

Special Issue: Research of Exercise and Cognitive Function

OBM Integrative and Complementary Medicine

2020, volume 5 , issue 1

doi:10.21926/obm.icm.2001002
Received: October 27, 2019

Accepted: December 31, 2019

Published: January 06, 2020

\begin{abstract}
Past research suggests that exercise is associated with improved working memory (WM) abilities, and that athletes have better executive functioning and WM skills than nonathletes. However, no studies to date have separated the effects of exercise from the effects of athletic participation when examining WM. This study had three primary goals: (1) to determine whether amateur college athletes have better auditory and visual WM than their non-athlete peers who exercise frequently and whether non-athlete frequent exercisers have better WM than non-athlete infrequent exercisers (2) to determine whether amateur participation in particular types of sports (team-based versus solo sports) corresponds to differences in auditory or visual WM, and (3) to examine whether gender plays a role in the relationships between exercise, athletic participation and WM. This study was a crosssectional, correlational design that examined WM in men versus women college students
\end{abstract}

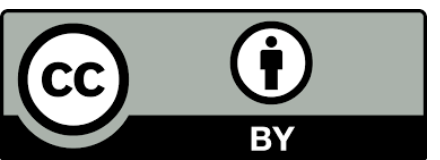

(C) 2020 by the author. This is an open access article distributed under the conditions of the Creative Commons by Attribution License, which permits unrestricted use, distribution, and reproduction in any medium or format, provided the original work is correctly cited. 
divided into four groups (team-sports athletes, solo-sports athletes, frequent exercisers, and infrequent exercisers). 153 college students completed five tests of auditory (Digit Span subtest, PASAT) and visual (Spatial Span subtest, N-Back, WCST) WM. Collegiate men who participated in team-based sports outperformed collegiate men who participated in solosports in auditory WM. The two non-athlete groups (frequent and infrequent exercisers) earned scores between those of the two athlete groups. Male infrequent exercisers demonstrated better visual WM than the other three male athlete/exerciser groups. In contrast, neither athletic participation nor exercise affected collegiate women's WM abilities. Our results did not support our hypothesis that all types of student athletes would exhibit better WM than students who exercise regularly but do not engage in competitive sports. Additionally, our data did not indicate that frequent exercise is associated with stronger WM skills than infrequent exercise in non-athlete college students. Participation in team-based sports was associated with better auditory WM skills than participation in solo sports, but this was only true for male, not female, athletes. Thus, gender was an important factor in delineating the relationships between exercise, athletic participation and WM.

\section{Keywords}

Athletes; college student; exercise; working memory

\section{Introduction}

Considerable research has supported the cognitive benefits of exercise and physical activity for individuals of all ages [1-5]. Cognitive functions that typically improve as a result of moderate to vigorous physical activity include attention [6, 7], short-term and long-term memory [8, 9] cognitive flexibility $[10,11]$ and processing speed [12].

Researchers have also evaluated the role of exercise in improving working memory (WM), the ability to actively monitor, manipulate, and process new incoming information, in both children and adults. In one study, children aged seven to nine were randomly assigned to participate in either an afterschool physical activity program or a control group. Those who engaged in moderate to vigorous physical activity demonstrated improvements in their visual WM, particularly when WM demands were high [13]. In another study, young adults who completed resistance or aerobic training showed faster reaction times immediately and 30 minutes after their exercise sessions on tasks that required visual WM than young adults who were in a seated rest condition [14]. The positive effects of exercise on WM also extend to adults across the life span. Across several past studies, adults ranging in age from 17 to over 70 years old have exhibited improvements in response to physical exercise in their accuracy and response times on tests of auditory WM like the Digit Span test, the Sternberg task, and the Paced Auditory Serial Addition Task [15-17], as well as on tests of visuospatial WM [18]. Thus, ample evidence indicates that increasing engagement in physical activity and exercise results in improvements in WM. None of these studies, however, examined naturalistic differences in WM abilities between individuals who elect to exercise frequently and individuals who do not engage in regular exercise routines.

Students involved in collegiate sports must engage in frequent exercise, but few studies have 
directly examined WM in amateur collegiate athletes. The limited number of studies that have evaluated WM-related task performance in athletes have examined differences across a variety of athlete groups based on their experience levels within the sport. These studies have supported the contention that, similar to exercise, increased participation in sports is associated with better WM skills. For example, experienced, expert golfers demonstrate better WM, more advanced problem solving, and more economical information processing skills than golf novices [19]. Similarly, expert martial artists are better able cognitively to process two different but related tasks simultaneously on a continuous performance task and on a cued continuous performance task compared to novices at the sport [20]. Thus, professional athletes appear to have better executive functioning skills than their non-professional-athlete peers. In a study that examined a general group of athletes who competed in volleyball or karate, both sports that require a high level of reactivity, individuals with greater athletic experience had faster WM reaction times than novice athletes, but they also made more errors when required to divide their attention [21]. These strong WM skills appear to put athletes at an advantage. Bijleveld \& Veling [22] found that WM capacity was positively associated with rapid decision making in tennis players and suggested that WM might be an important factor separating chokers from non-chokers during competition. Additionally, Furley \& Memmert [23] found that basketball and ice hockey players with high WM capacity demonstrated better complex WM and decision-making particularly in the presence of auditory distractions while engaged in a basketball task than players with lower WM capacity.

Together these past studies suggest that physical activity improves WM performance and that increased involvement and expertise in sports also corresponds with better WM skills. However, none of these past studies separated the role of regular physical activity and exercise from that of participation in formal sports by including an exercising non-athlete control group against which to compare the athletes. For example, Furley \& Memmert [23] administered a visuospatial WM test to college athletes involved in team-ball sports and to non-athlete college students who never participated in team-ball sports. They found no differences in visuospatial WM between these two groups of students. They attributed their non-significant finding to the sequential nature of the WM assessment measure they used, which, they argued, does not parallel the type of visuospatial WM skills required when playing basketball [23]. Another study compared the WM capacity of non-athlete college students to that of team sport athletes and found no significant differences [24]. In both of the above studies, the researchers did not characterize the exercise habits of their non-athlete college students. Thus, it is possible that their athletes and non-athletes were similar in the amount of physical activity they engaged in, minimizing differences between the groups in WM. This raises the possibility that the intense regular exercise engaged in by professional or amateur college athletes may account for the superior WM and executive functioning skills documented in past studies rather than these skills being attributable to involvement in sports perse.

Given the past literature, the first goal of our study was to determine whether amateur athletes involved in college sports outperform college students who exercise regularly in their auditory and visual WM, and whether non-athlete students who choose to engage in physical activity on a regular basis outperform those non-athlete students who do not exercise regularly on a variety of WM tests. We hypothesized that engagement in exercise, even by non-athletes, would correspond with better WM skills and that involvement in formal sports would confer additional advantage to WM performance. Thus, we hypothesized that athletes would outperform non-athletes and that 
non-athletes who exercise regularly would outperform non-athletes who do not exercise regularly on tests of WM.

If athletic participation itself contributes to the enhanced WM abilities of athletes, this may be due to the WM demands associated with competitive sports. One past study suggested that athletes who compete in sports that require more WM capacity score higher on tests of WM ability than other athletes [24]. Outside of this particular study, however, this phenomenon has not been explored in the literature. Thus, the second goal of our study was to determine whether participation in team-focused sports versus solo sports related to differences in auditory or visual WM. We defined team-focused sports (such as, football, basketball, soccer and volleyball) as those that require individuals to interact with their teammates to achieve their athletic goals while simultaneously working against another team of opponents, whereas we defined solo sports (like tennis, swimming, or running track or cross country) as those that primarily depend on individual performance for success. Although all sports likely require strong WM skills, WM demands may be greater for amateur athletes involved in team-focused sports than those involved in solo sports. With large numbers of players (both teammates and opponents) to track simultaneously and with many irrelevant distractions from other athletes and crowds, team-sports athletes may gain more experience with their visual and auditory WM skills while practicing and competing than their solosport athlete peers. Thus, we hypothesized that team-sports athletes would perform better on auditory and visual WM tests than solo-sports athletes.

The third goal of our study was to investigate whether gender plays a role in the hypothesized relationships between exercise, athletic involvement and WM. Previous research has identified gender differences in exercise-related beliefs and exercise behaviors in non-athletes [25, 26], motivation for participation in collegiate athletics [27], perception and interpretation of competitiveness in college athletes [28], and goal orientation and attributional style within competitive vs recreational sports [29]. Past research has also documented significant gender differences in the auditory, visual and spatial WM abilities of college students in general [30-32]. Because gender relates to both WM skills and to exercise and sports participation, we aimed to determine whether the relationships between exercise, athletic involvement and WM were similar or different across male and female college students.

\section{Materials and Methods}

\subsection{Participants}

We recruited 153 college student participants from multiple sources. Students in introductory and lower level psychology courses completed a packet of pre-testing questionnaires that included items asking about their physical activity/exercise levels and their participation in organized collegiate athletics. We invited students who reported frequent (exercise three or more days a week) or infrequent (exercise less than once a week) physical activity or who identified themselves as being on the roster of an amateur National Collegiate Athletic Association (NCAA) or club sport team at the university to participate in the study. We also utilized official team rosters and emailed university athletes to invite them to participate. Based on their self-reported exercise frequency (non-athletes) and verification with online team rosters (athletes), we classified our 153 participants into one of four groups: (a) Team Sports Athletes (TSA) (b) Solo Sports Athletes (SSA) 
(c) Non-Athlete Frequent Exercisers (FE), and (d) Non-Athlete Infrequent Exercisers (IE). We defined team sports as those that require individuals to interact with their teammates to achieve their athletic goals and to assess the location or status of multiple members of the opposing team frequently during play. Examples of team sports included: football, basketball, soccer and volleyball. We defined solo sports as those in which athletic achievement primarily depends on individual performance. Examples of solo sports included: tennis, swimming, running track and cross-country.

\subsection{Materials}

\subsubsection{Demographic Characteristics and Physical Activity}

All students completed a demographic questionnaire that asked their age, gender, ethnicity and year in college. The physical activity section of the questionnaire consisted of items inquiring about their intensity and frequency of physical activity and their participation in collegiate sports. Athletes indicated the specific sports in which they participated, denoting their "primary" sport, which we used to classify them as a team-sports or a solo-sports athlete.

\subsubsection{Working Memory}

Digit Span (DS). On the DS subtest from the Wechsler Memory Scale-Third Edition [33] participants hear increasingly longer sequences of single digit numbers. For the first portion of this test, participants repeat the sequence out loud in order of presentation (forward span). For the second portion, they recite the sequence in reverse order (backward span).

Paced Auditory Serial Addition Test (PASAT). During the PASAT [34], participants hear a sequence of single digit numbers. They add adjacent digits together and verbally report the sum. While calculating the sum, they must also remember the last digit they heard in order to add it to the next number presented. The digits occur three seconds apart during the first trial (PASAT 3) and two seconds apart during the second trial (PASAT 2).

Spatial Span (SS). Also from the Wechsler Memory Scale-Third Edition [35], a visual analog of the DS test, during the SS subtest, participants watch the examiner tap increasingly longer sequences of raised, blue blocks positioned arbitrarily on a white board. Participants tap the blocks in the same order they witnessed (forward span) or in the reverse order (backward span).

N-Back. During the N-Back [36, 37], participants view a series of letters that appear serially on a computer screen. Their task is to inform the examiner whenever a letter is identical to the letter that came immediately before it (1-back). In subsequent trials, the task becomes more difficult as participants attempt to inform the examiner when the letter matches the one that came two before it (2-back) or three before it (3-back).

Wisconsin Card Sorting Test (WCST). The WCST [38] is a test of flexibility of thinking and of the complex problem-solving component of WM. Participants view a set of four key cards on a computer screen. They then see a single stimulus card that shares attributes with some or all of the key cards. Participants must make a match between the stimulus card and the one key card they believe it matches. They are not told how to sort the cards, but after each response, they receive feedback from the computer about whether their sort was correct or incorrect. Using this feedback, they must determine the correct sorting rule. After they make a specified number of 
correct sorts using the first rule, the rule for sorting the cards changes without forewarning. They must then identify a new sorting rule and apply it consistently until the rule changes again.

\subsection{Procedure}

In accordance with the Institutional Review Board approved research protocol, participants completed an individual testing session lasting approximately one hour and were paid a small sum or awarded extra credit in a psychology course for their participation. After giving informed consent, participants completed the demographic questionnaire and the five tests of WM.

\subsection{Design and Analyses}

This cross-sectional, correlational study involved two between-subjects independent variables: group (team-sports athletes, solo-sports athletes, frequent exercisers, and infrequent exercisers) and gender (male versus female). The study included seven WM outcome measures: Digit Span total score (forward span + backward span), PASAT total score (3 second +2 second), Spatial Span total score (forward span + backward span), N-Back total score (1-back + 2-back + 3-back), as well as total correct, non-perseverative errors and perseverative errors on the WCST. Because all of these outcome measures assessed similar constructs, we analyzed the data with a 4 (Group) $\times 2$ (Gender) multivariate analysis of variance (MANOVA) with the seven outcome measures serving as dependent variables. We used a MANOVA to maximize our power to detect significant effects. We used Wilks' Lambda to correct for possible violations of the assumption of homogeneity of treatment difference variances when determining statistical significance. When justified by significant interaction effects in the MANOVA, we ran simple main effect analyses followed by group comparisons using Tukey's test to control the probability of committing a Type 1 error.

\section{Results}

\subsection{Demographic Comparisons}

Table 1 summarizes the demographic characteristics of the male and female participants within each of the four athlete/exerciser groups. Gender was not distributed evenly across the four athlete/exercise groups $\left(\chi^{2}(n=153, d f=3)=12.92, p<.01\right)$, but the distribution of ethnicity was statistically equivalent across all eight groups, $\chi^{2}(n=153, d f=18)=15.76, p=.61$. Similarly, the eight athlete by gender groups were not statistically different in age or class year (all main and interaction effect $p s>.05)$. 
Table 1 Demographic characteristics and working memory means (SEs) of the male and female participants in each of the four athlete/exerciser groups.

\begin{tabular}{|c|c|c|c|c|c|c|c|c|}
\hline & \multicolumn{8}{|c|}{ Group Means (SE) ( $n=153)$} \\
\hline & \multicolumn{4}{|c|}{ Athletes $(n=77)$} & \multicolumn{4}{|c|}{ Non-Athletes $(n=76)$} \\
\hline & \multicolumn{2}{|c|}{$\begin{array}{c}\text { Team Sports } \\
\text { Athletes } \\
(n=42) \\
\end{array}$} & \multicolumn{2}{|c|}{$\begin{array}{c}\text { Solo Sports } \\
\text { Athletes } \\
(n=35)\end{array}$} & \multicolumn{2}{|c|}{$\begin{array}{c}\text { Frequent } \\
\text { Exercisers } \\
(n=43)\end{array}$} & \multicolumn{2}{|c|}{$\begin{array}{l}\text { Infrequent } \\
\text { Exercisers } \\
(n=33)\end{array}$} \\
\hline & $\begin{array}{l}\text { Male } \\
(n=25)\end{array}$ & $\begin{array}{c}\text { Female } \\
(n=17)\end{array}$ & $\begin{array}{l}\text { Male } \\
(n=16)\end{array}$ & $\begin{array}{c}\text { Female } \\
(n=19)\end{array}$ & $\begin{array}{l}\text { Male } \\
(n=14)\end{array}$ & $\begin{array}{c}\text { Female } \\
(n=29)\end{array}$ & $\begin{array}{l}\text { Male } \\
(n=7)\end{array}$ & $\begin{array}{l}\text { Female } \\
(n=26) \\
\end{array}$ \\
\hline & \multicolumn{8}{|c|}{ Demographic Characteristics } \\
\hline Age (in years) & $\begin{array}{l}19.72 \\
(0.25)\end{array}$ & $\begin{array}{l}19.77 \\
(0.31)\end{array}$ & $\begin{array}{l}20.00 \\
(0.32)\end{array}$ & $\begin{array}{l}19.47 \\
(0.29)\end{array}$ & $\begin{array}{l}19.43 \\
(0.34)\end{array}$ & $\begin{array}{l}19.35 \\
(0.24)\end{array}$ & $\begin{array}{l}19.71 \\
(0.48)\end{array}$ & $\begin{array}{l}19.46 \\
(0.25)\end{array}$ \\
\hline $\begin{array}{l}\text { Year in } \\
\text { College }\end{array}$ & $\begin{array}{c}2.36 \\
(0.22)\end{array}$ & $\begin{array}{c}2.29 \\
(0.26)\end{array}$ & $\begin{array}{c}2.25 \\
(0.27)\end{array}$ & $\begin{array}{c}1.84 \\
(0.25)\end{array}$ & $\begin{array}{c}1.86 \\
(0.29)\end{array}$ & $\begin{array}{c}1.93 \\
(0.20)\end{array}$ & $\begin{array}{c}2.43 \\
(0.42)\end{array}$ & $\begin{array}{c}1.96 \\
(0.22)\end{array}$ \\
\hline \multirow[t]{2}{*}{$\begin{array}{l}\text { Ethnicity } \\
\text { (\% White) }\end{array}$} & $88 \%$ & $94 \%$ & $81 \%$ & $84 \%$ & $71 \%$ & $93 \%$ & $100 \%$ & $92 \%$ \\
\hline & \multicolumn{8}{|c|}{ Working Memory } \\
\hline \multicolumn{9}{|l|}{ Auditory WM } \\
\hline Digit Span & $\begin{array}{l}20.84 \\
(0.77)\end{array}$ & $\begin{array}{l}17.80 \\
(0.99)\end{array}$ & $\begin{array}{l}16.75 \\
(0.96)\end{array}$ & $\begin{array}{l}18.90 \\
(0.91)\end{array}$ & $\begin{array}{l}18.83 \\
(1.12)\end{array}$ & $\begin{array}{l}18.50 \\
(0.73)\end{array}$ & $\begin{array}{l}19.57 \\
(1.45)\end{array}$ & $\begin{array}{l}17.62 \\
(0.75)\end{array}$ \\
\hline PASAT & $\begin{array}{l}94.08 \\
(3.31)\end{array}$ & $\begin{array}{l}85.40 \\
(4.23)\end{array}$ & $\begin{array}{l}89.38 \\
(4.14)\end{array}$ & $\begin{array}{l}80.61 \\
(3.91)\end{array}$ & $\begin{array}{l}95.42 \\
(4.78)\end{array}$ & $\begin{array}{l}87.25 \\
(3.13)\end{array}$ & $\begin{array}{c}101.14 \\
(6.26)\end{array}$ & $\begin{array}{l}78.58 \\
(3.25)\end{array}$ \\
\hline Visual WM & & & & & & & & \\
\hline Spatial Span & $\begin{array}{l}18.80 \\
(0.64)\end{array}$ & $\begin{array}{l}18.07 \\
(0.83)\end{array}$ & $\begin{array}{l}18.38 \\
(0.81)\end{array}$ & $\begin{array}{l}19.33 \\
(0.76)\end{array}$ & $\begin{array}{l}19.58 \\
(0.93)\end{array}$ & $\begin{array}{l}18.61 \\
(0.61)\end{array}$ & $\begin{array}{l}22.71 \\
(1.22)\end{array}$ & $\begin{array}{l}17.39 \\
(0.63)\end{array}$ \\
\hline N-back & $\begin{array}{l}42.12 \\
(0.81)\end{array}$ & $\begin{array}{l}40.07 \\
(1.05)\end{array}$ & $\begin{array}{l}40.25 \\
(1.01)\end{array}$ & $\begin{array}{l}39.61 \\
(0.96)\end{array}$ & $\begin{array}{l}42.25 \\
(1.17)\end{array}$ & $\begin{array}{l}41.68 \\
(0.77)\end{array}$ & $\begin{array}{l}42.14 \\
(1.53)\end{array}$ & $\begin{array}{l}40.12 \\
(0.79)\end{array}$ \\
\hline \multicolumn{9}{|c|}{ Wisconsin Card Sorting Test } \\
\hline Total Correct & $\begin{array}{l}67.96 \\
(1.80)\end{array}$ & $\begin{array}{l}69.07 \\
(2.33)\end{array}$ & $\begin{array}{l}67.00 \\
(2.26)\end{array}$ & $\begin{array}{l}66.11 \\
(2.13)\end{array}$ & $\begin{array}{l}69.59 \\
(2.61)\end{array}$ & $\begin{array}{l}65.72 \\
(1.71)\end{array}$ & $\begin{array}{l}61.71 \\
(3.42)\end{array}$ & $\begin{array}{l}64.65 \\
(1.77)\end{array}$ \\
\hline $\begin{array}{l}\text { Non- } \\
\text { Perseverative } \\
\text { Errors }\end{array}$ & $\begin{array}{c}6.08 \\
(1.06)\end{array}$ & $\begin{array}{c}9.40 \\
(1.96)\end{array}$ & $\begin{array}{c}5.44 \\
(0.57)\end{array}$ & $\begin{array}{l}5.72 \\
(1.10)\end{array}$ & $\begin{array}{c}6.75 \\
(1.87)\end{array}$ & $\begin{array}{c}8.29 \\
(1.79)\end{array}$ & $\begin{array}{l}13.00 \\
(9.01)\end{array}$ & $\begin{array}{c}5.54 \\
(0.88)\end{array}$ \\
\hline $\begin{array}{l}\text { Perseverative } \\
\text { Errors }\end{array}$ & $\begin{array}{c}6.32 \\
(1.34)\end{array}$ & $\begin{array}{c}8.47 \\
(1.74)\end{array}$ & $\begin{array}{c}5.81 \\
(1.68)\end{array}$ & $\begin{array}{c}8.33 \\
(1.58)\end{array}$ & $\begin{array}{c}7.58 \\
(1.94)\end{array}$ & $\begin{array}{c}7.82 \\
(1.27)\end{array}$ & $\begin{array}{c}6.00 \\
(2.54)\end{array}$ & $\begin{array}{c}6.62 \\
(1.32)\end{array}$ \\
\hline
\end{tabular}




\subsection{Working Memory}

Scores on the seven tests of WM are also summarized in Table 1. Scores on all of the WM measures were available for 147 participants.

In the multivariate analysis, there was no significant main effect of group $(F(21,382.45)=1.35$, $\left.p=.14, \eta_{p}{ }^{2}=.07\right)$, but a significant main effect of gender emerged, $F(7,133)=3.41, p<.01, \eta_{p}^{2}$ $=.15$. Univariate analyses indicated gender differences on the PASAT $(F(1,139)=16.10, p<.001$, $\left.\eta_{p}^{2}=.10\right)$ and on the Spatial Span Test, $F(1,139)=6.80, p=.01, \eta_{p}^{2}=.05$. Males outperformed females on both of these measures of WM.

In addition to the main effect of gender, the group by gender interaction reached statistical significance in the MANOVA, $F(21,382.45)=1.85, p<.05, \eta_{p}^{2}=.09$. The associated univariate analyses revealed significant group by gender interactions for both Digit Span $(F(3,139)=2.93, p$ $\left.<.05, \eta_{\mathrm{p}}{ }^{2}=.06\right)$ and Spatial Span, $F(3,139)=4.37, p<.01, \eta_{\mathrm{p}}{ }^{2}=.09$. Additionally, there was a strong trend towards a significant group by gender interaction for WCST non-perseverative errors, $F(3$, $139)=2.28, p=.08, \eta_{p}^{2}=.05$. Figure 1 displays the average scores of each of the eight athlete/exerciser by gender groups on these three tests.

Follow-up simple main effect analyses examining group differences separately for the men and women in the study indicated that athletic participation and exercise did not affect the WM abilities of female participants as measured by the Digit Span test $\left(F(3,83)=0.46, p=.72, \eta_{p}^{2}\right.$ $=.02)$, the Spatial Span test $\left(F(3,83)=1.20, p=.32, \eta_{p}{ }^{2}=.04\right)$, or non-perseverative errors on the WCST, $F(3,83)=1.46, p=.23, \eta_{p}{ }^{2}=.05$. In contrast, group membership had a significant impact on the WM of men on both the Digit Span test $\left(F(3,56)=4.50, p<.01, \eta_{p}{ }^{2}=.19\right)$ and the Spatial Span test $\left(F(3,56)=4.62, p<.01, \eta_{p}^{2}=.20\right)$, but not on the WCST, $F(3,56)=1.26, p=.30, \eta_{p}{ }^{2}=.06$. Post hoc comparisons using Tukey's test revealed that males in the TSA group scored significantly higher on the Digit Span test than male participants in the SSA group, $p<.05$. Males in the FE and IE groups did not differ significantly from either of the athlete groups or from each other in their Digit Span scores. For Spatial Span, the pattern of results was somewhat different. Male participants in the IE group significantly outscored male participants in all three of the other groups on this measure, (all ps < .05); the male TSA, SSA, and FE groups performed similarly, and not significantly differently from one another, on the Spatial Span test.

When we examined gender differences within each group, TSA men outperformed TSA women on the Digit Span test $\left(F(1,38)=5.68, p<.05, \eta_{p}{ }^{2}=.13\right)$, whereas no gender differences emerged within the other three groups on this measure. For Spatial Span, IE men outperformed IE women, $\left(F(1,31)=11.97, p<.01, \eta_{p}{ }^{2}=.28\right)$, but no gender differences were apparent for the TSA, SSA or FE groups. No gender differences emerged within any of the athlete groups for WCST nonperseverative errors. 
(a)

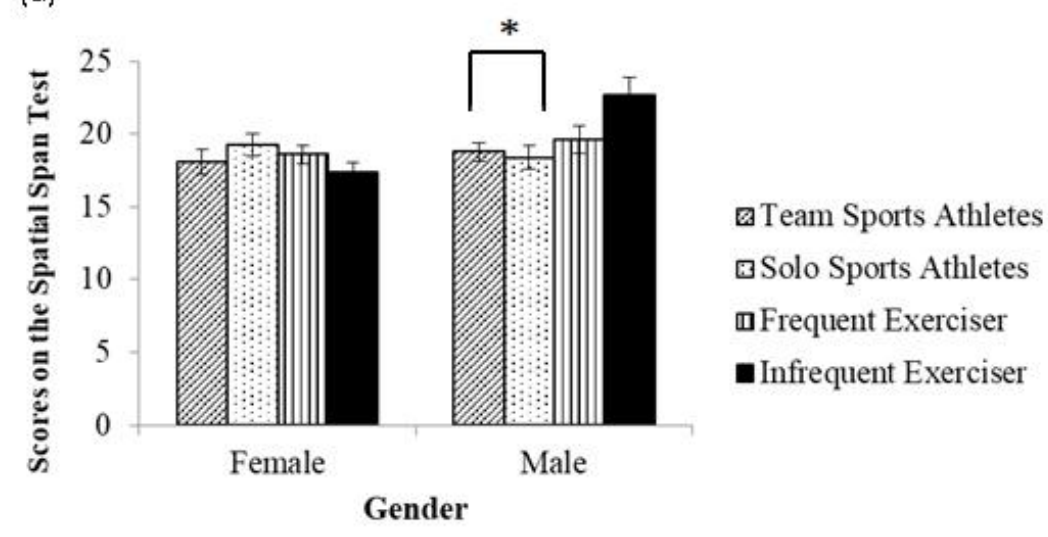

(b)

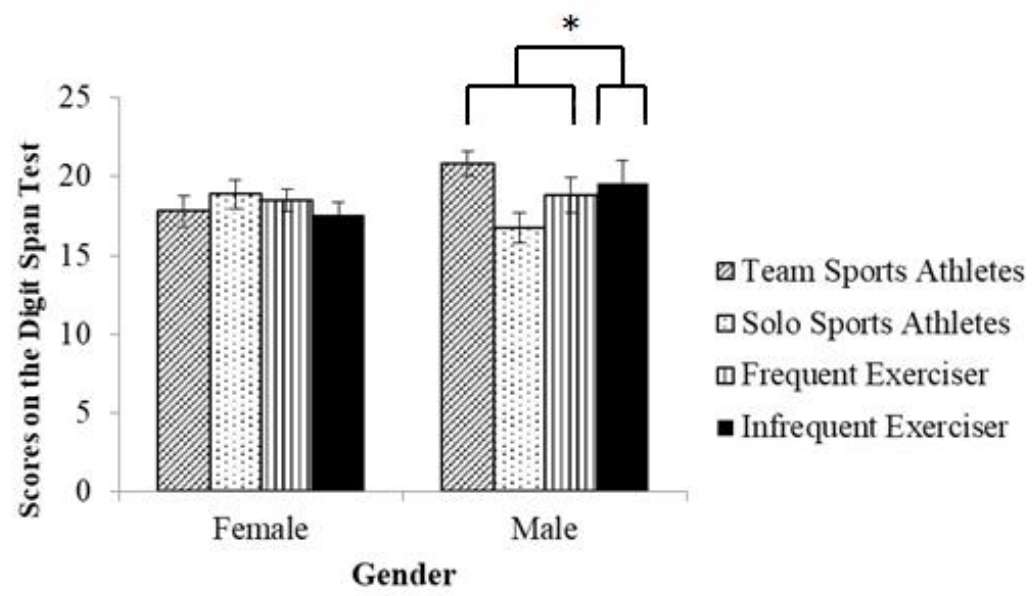

(c)

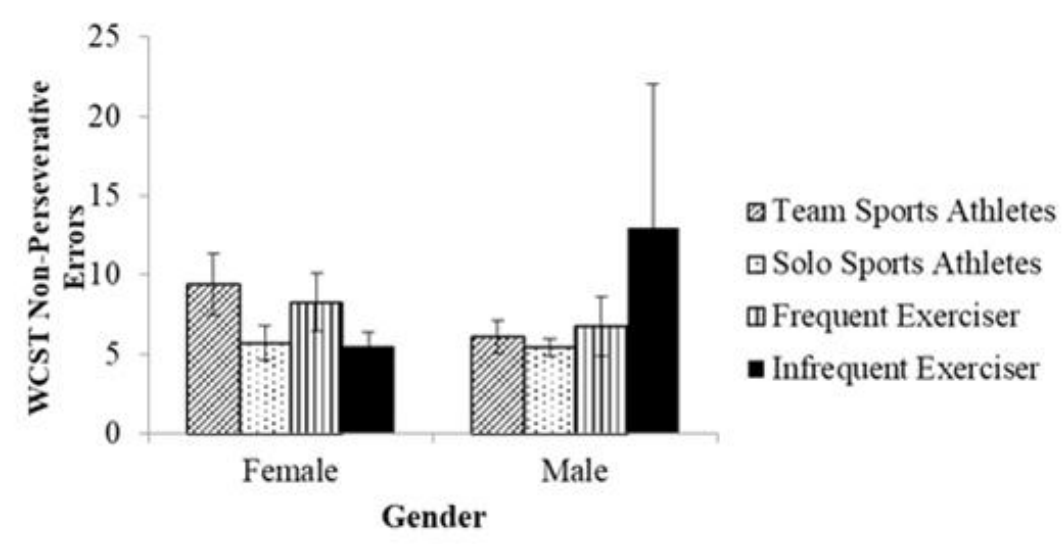

Figure 1 Group by Gender Interactions on (a) Digit Span, (b) Spatial Span, and (c) WCST non-perseverative errors. Error bars represent \pm 1 standard error of the mean. Significant differences $(p<.05)$ between groups are denoted with asterisks. Specifically, Male Team Sports Athletes significantly outscored Male Solo Sports Athletes on the Digit Span test (Panel a), and Male Infrequent Exercisers significantly outscored all three other male groups (Team Sports Athletes, Solo Sports Athletes and Frequent Exercisers) on the Spatial Span test (Panel b). None of the follow-up comparisons reached significance for WCST non-perseverative errors (Panel c). 


\section{Discussion}

We examined the auditory and visual WM skills of competitive amateur collegiate athletes involved in either team sports or solo sports and compared them to the WM skills of non-athletes, some of whom exercise frequently and some of whom exercise infrequently. We additionally explored the potential role of gender in the relationships between athletic participation, exercise, and WM. Our goal was to separate the effects of frequent exercise on WM from the effects of participation in competitive sports, since past research has not examined this potential confounding factor [13-17]. We also aimed to examine the effect of frequent exercise on WM abilities in a naturalistic setting since past research has typically experimentally controlled physical activity levels when investigating how they impact WM $[19,20,23,24]$. Consistent with our expectations, athletic involvement, exercise habits and gender all related to WM performance. However, the nature of these relationships did not always support our hypotheses. Only male team sports athletes demonstrated an auditory WM advantage, and visual WM skills were strongest in male college students who exercise infrequently, rather than frequently. Consistent with the past literature [30-32], we documented gender differences in some aspects of WM, with males performing better than females on tests of both auditory (PASAT) and visual (Spatial Span) WM. More importantly, and consistent with our hypothesis, we found that the relationships between athletic participation, exercise and WM depended on gender.

Our results do not suggest that participation in formal athletics globally relates to better WM. We did not find any differences in WM between women based on their athletic or exercise status. All four of the female groups (team-sports athletes, solo-sports athletes, frequent exercisers and infrequent exercisers) performed similarly on seven measures of WM. In contrast, for men, participation in team-sports athletics was associated with enhanced auditory WM compared to participation in solo-sports athletics. Although this suggests that competing in team sports, which may exert heavy demands on working memory, may result in better WM skills, our results are correlational. We cannot determine whether young men with better auditory WM are more likely to excel at and participate in team sports, whether participation in team sports improves auditory WM, or whether a combination of these two possibilities is true. Regardless of the reason for this finding, our results suggest that the type of athletic involvement (team-based sports versus solo sports) may be an important variable to consider in future research focused on the WM abilities of athletes since the two athlete groups in our study varied in their auditory WM skills.

Considering our data from a different angle, men involved in team-based sports outperformed women involved in team-based sports on the Digit Span test. Perhaps this reflects differences in the WM demands associated with the particular sports our male team-sports athletes competed in (e.g., football) versus those our female teams-sports athletes competed in (e.g., volleyball). These sports could differ in their reliance on or potential to improve WM skills, but further research would be necessary to address this possibility.

Even though male team-sports athletes outperformed male solo-sports athletes on the Digit Span test, their auditory WM abilities were not significantly better than their non-athlete male peers who exercised frequently or their non-athlete male peers who exercised infrequently. We also failed to find the hypothesized advantage in WM for non-athlete men or women college students who elect to include exercise in their regular routine versus their non-athlete peers who do not. In fact, contrary to our hypothesis, males who exercise infrequently performed better on 
the Spatial Span WM test than male team-sports athletes, solo-sports athletes and non-athletes who exercise frequently. Thus, we did not find that exercise in and of itself corresponded with enhanced WM, contrary to past studies in the literature that have documented improvement in auditory and visual WM in response to experiment-induced increases in physical activity [25-27]. One possible explanation for this contradictory result may be that, in past studies, improvements in WM occurred relative to each individual's baseline skills in response to the increased levels of physical activity demanded by the experiment, but individual differences in naturalistic exercise habits do not similarly correspond to notable between group differences in WM.

\section{Limitations and Future Research}

Prior to generalizing our results to all college students or young athletes, it is important to consider the limitations of our study. We recruited the participants in this study from a small liberal arts university with a somewhat limited number of sports options available to them. Therefore, these results need to be considered within this particular context and should be compared to those from athletes from larger universities with multiple sports or physical activity options through future research initiatives. Additionally, because our participants were all college students, they were amateur, not professional athletes. Our results may not generalize to athletes who participate in team-focused or solo sports professionally.

Our study was also limited by the way in which we classified our participants into groups. We did not ask the amateur collegiate athletes who participated in our study whether they competed in more than one sport. Participating in an NCAA-level sport is demanding and likely leaves little time for additional athletic participation, but the club sports athletes in our sample may have engaged in more than one sport that might have fit another category (team-based or solo), potentially confounding our results. We also classified participants into frequent exercisers and infrequent exercisers based on their self-reported exercise habits rather than collecting objective data on how frequently students in our study engaged in regular physical activity. Because students may have misrepresented their typical exercise routines due to subtle biases in their selfreports, we selected extreme groups to include in our sample to prevent misclassification of nonexercisers as exercisers and vice versa.

Although our sample size was fairly large $(n=153)$, the gender distribution across our groups was imbalanced. Thus, some of our cell sizes were fairly small. As such, our results, particularly those that failed to reach significance, may reflect our limited sample size and the associated lack of power rather than a lack of true differences amongst athlete and exercise groups in the general population. Our sample also may not have been fully representative of the full range of college athletes, nor of frequent vs infrequent exercisers. We recruited athletes directly from rosters; some teams were responsive and others were not. Most of our non-athletes came from a pool of participants drawn from enrollment in psychology courses at our university. Incorporating a wider variety of students (athletes and non-athletes) and a more balanced gender distribution across groups in future studies would improve the generalizability of our results.

\section{Conclusions}

Our study highlights differences in WM associated with exercise and participation in formal amateur athletics amongst college students. These factors related to both auditory and visual WM 
for collegiate men, but not collegiate women, suggesting that future studies examining relationships between physical activity (athletics or regular exercise) and WM should take gender into account. We also found differences in WM based on whether our male athletes participated in a team-focused sport or a solo-focused sport, indicating that the type of sport an athlete competes in is an important consideration in future research examining WM abilities in this population.

\section{Author Contributions}

Tara T. Lineweaver and Suneeta Kercood collaboratively designed the research study described in this manuscript and assumed primary responsibility for manuscript preparation. Elyse B. Morgan, Shelby L. Rampone, Colleen C. Frank, Scott A. McLuckie, and Mack F. Reed shared responsibility for coordinating and implementing data collection efforts: recruiting participants, conducting individual testing sessions, and scoring and entering data. All authors contributed to data analysis.

\section{Competing Interests}

The authors have declared that no competing interests exist.

\section{References}

1. Colcombe S, Kramer AF. Fitness effects on the cognitive function of older adults: A metaanalytic study. Psychol Sci. 2003; 14: 125-130.

2. Davranche K, McMorris T. Specific effects of acute moderate exercise on cognitive control. Brain Cogn. 2009; 69: 565-570.

3. Sibley BA, Etnier JL. The relationship between physical activity and cognition in children: $A$ meta-analysis. Pediatr Exerc Sci. 2003; 15: 243-256.

4. Tomporowski PD, Ellis NR. Effects of exercise on cognitive processes: A review. Psychol Bull. 1986; 99: 338-346.

5. Welsh MC, Labbé EE. Children and aerobic exercise: A review of cognitive and behavioral effects. J Exp Child Psychol. 1994; 58: 405-417.

6. Mahar MT. Impact of short bouts of physical activity on attention-to-task in elementary school children. Prev Med. 2011; 52: S60-S64.

7. Tine MT, Butler AG. Acute aerobic exercise impacts selective attention: An exceptional boost in lower-income children. Edu Psychol. 2012; 32: 821-834.

8. Coles K, Tomporowski PD. Effects of acute exercise on executive processing, short-term and long-term memory. J Sports Sci. 2008; 26: 333-344.

9. Tomporowski P, Stueck M. Short-term effects of aerobic exercise on executive processing, memory, and emotion. Med Sci Sports Exerc. 2004; 36: S273-S274.

10. Masley S, Roetzheim R, Gualtieri T. Aerobic exercise enhances cognitive flexibility. J Clin Psychol Med Settings. 2009; 16: 186-193.

11. Netz $\mathrm{Y}$, Tomer R, Axelrad S, Argov E, Inbar O. The effect of a single aerobic training session on cognitive flexibility in late middle-aged adults. Int J Sports Med. 2007; 28: 82-87.

12. Tam ND. Improvement of processing speed in executive function immediately following an increase in cardiovascular activity. Cardiovasc Psychiatry Neurol. 2013; 2013: 1-6. 
13. Kamijo K, Pontifex MB, O'Leary KC, Scudder MR, Wu CT, Castelli DM, et al. The effects of an afterschool physical activity program on working memory in preadolescent children. Dev Sci. 2011; 14: 1046-1058.

14. Pontifex MB, Hillman CH, Fernhall B, Thompson KM, Valentini TA. The effect of acute aerobic and resistance exercise on working memory. Med Sci Sports Exerc. 2009; 41: 927-934.

15. Lambourne $K$, Audiffren $M$, Tomporowski PD. Effects of acute exercise on sensory and executive processing tasks. Med Sci Sports Exerc. 2010; 42: 1396-1402.

16. Martins QA, Kavussanu M, Willoughby A, Ring C. Moderate intensity exercise facilitates working memory. Psychol Sport Exerc. 2013; 14: 323-328.

17. Guiney $\mathrm{H}$, Machado L. Benefits of regular aerobic exercise for executive functioning in healthy populations. Psychon Bull Rev. 2013; 20: 73-86.

18. Weinstein AM, Voss MW, Prakash RS, Chaddock L, Szabo A, White SM, et al. The association between aerobic fitness and executive function is mediated by prefrontal cortex volume. Brain Behav Immun. 2012; 26: 811-819.

19. Baumeister J, Reinecke K, Liesen $H$, Weiss $M$. Cortical activity of skilled performance in a complex sports related motor task. Eur J Appl Physiol. 2008; 104: 625-631.

20. Sanchez-Lopez J, Fernandez T, Silva-Pereyra J, Mesa JAM, Di Russo F. Differences in visuomotor control in skilled vs. novice martial arts athletes during sustained and transient attention tasks: A motor-related cortical potential study. PloS One. 2014; 9: e91112: 1-9.

21. Fontani G, Lodi L, Felici A, Migliorini S, Corradeschi F. Attention in athletes of high and low experience engaged in different open skill sports. Percept Mot Skills. 2006; 102: 791-805.

22. Bijleveld E, Veling H. Separating chokers from nonchokers: Predicting real-life tennis performance under pressure from behavioral tasks that tap into working memory functioning. J Sport Exerc Psychol. 2014; 36: 347-356.

23. Furley PA, Memmert D. Working memory capacity as controlled attention in tactical decision making. J Sport Exerc Psychol. 2012; 34: 322-344.

24. Mayers LB, Redick TS, Chiffriller SH, Simone AN, Terraforte KR. Working memory capacity among collegiate student athletes: Effects of sport-related head contacts, concussions, and working memory demands. J Clin Exp Neuropsychol. 2011; 33: 532-537.

25. Magoc D, Tomaka J, Shamaley AG, Bridges A. Gender differences in physical activity and related beliefs among Hispanic college students. Hisp J Behav Sci. 2016; 38: 279-290.

26. Garcia AW, Broda MAN, Frenn M, Coviak C, Pender NJ, Ronis DL. Gender and developmental differences in exercise beliefs among youth and prediction of their exercise behavior. J Sch Health. 1995; 65: 213-219.

27. Flood SE, Hellstedt JC. Gender differences in motivation for intercollegiate athletic participation. J Sport Behav. 1991; 14: 159.

28. Warner S, Dixon MA. Competition, gender and the sport experience: An exploration among college athletes. Sport Educ Soc. 2015; 20: 527-545.

29. Hanrahan SJ, Cerin E. Gender, level of participation, and type of sport: Differences in achievement goal orientation and attributional style. J Sci Med Sport. 2009; 12: 508-512.

30. Kercood S, Lineweaver TT, Kugler J. gender differences in self-reported symptomatology and working memory in college students with ADHD. J Postsecond Educ Disabil. 2015; 28: 41-56.

31. Miller $\mathrm{H}$, Bichsel J. Anxiety, working memory, gender, and math performance. Pers Individ Dif. 2004; 37: 591-606. 
32. Geiger JF, Litwiller RM. Spatial working memory and gender differences in science. J Instruc Psych. 2005; 32: 49-57.

33. Wechsler D. WAIS-III: Wechsler adult intelligence scale administration and scoring manual. San Antonio, TX: Psychological Corporation; 1997.

34. Gronwall DM, Sampson H. The psychological effects of concussion. Auckland, New Zealand: Aukland University Press; 1974.

35. Wechsler D. WMS-III: Administration and scoring manual. San Antonio, TX: The Psychological Corporation. 1997.

36. Cohen JD, Forman SD, Braver TS, Casey B, Servan-Schreiber D, Noll DC. Activation of the prefrontal cortex in a nonspatial working memory task with functional MRI. Hum Brain Mapp. 1994; 1 : 293-304.

37. Smith EE, Jonides J. Working memory: A view from neuroimaging. Cogn Psychol. 1997; 33: 5-42.

38. Heaton RK, Chelune GJ, Talley JL, Kay GG, Curtiss G. Wisconsin card sorting test manual: Revised and expanded. Lutz, FL: Psychological Assessment Resources; 1993.

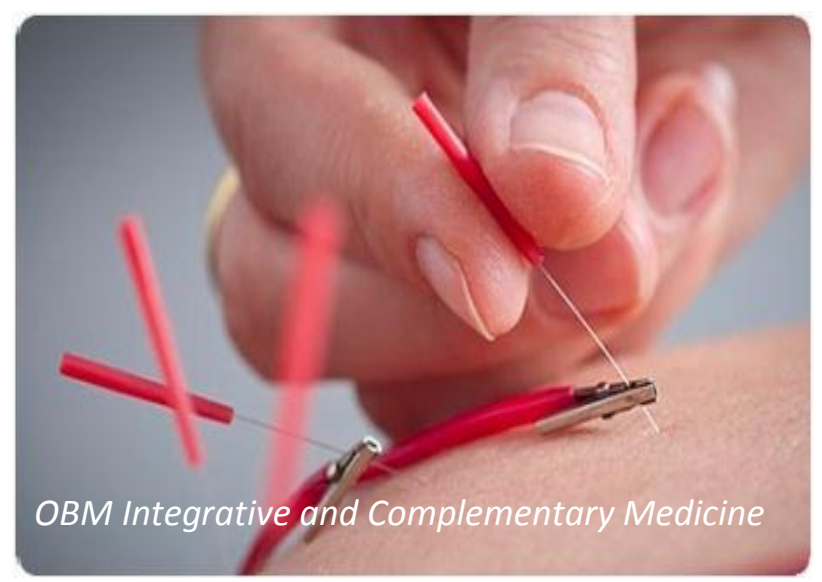

Enjoy OBM Integrative and Complementary Medicine by:

1. Submitting a manuscript

2. Joining in volunteer reviewer bank

3. Joining Editorial Board

4. Guest editing a special issue

For more details, please visit: http://www.lidsen.com/journals/icm 